\title{
ЗАСТОСУВАННЯ МЕТРИКИ ХАУСДОРФА ДЛЯ ВИЗНАЧЕННЯ НЕТИПОВИХ КАРДІОЦИКЛІВ У ТРИВИМІРНОМУ ФАЗОВОМУ ПРОСТОРІ КООРДИНАТ ВЕКТОРКАРДІОГРАМИ
}

\author{
В. В. Вишневський, Т. М. Романенко \\ Інститут проблем математичних машин і систем НАН України
}

\begin{abstract}
Сигнал електрокардіограми відноситься до циклічних сигналів, у яких, на відміну від періодичних сигналів, можна виділити подібні, але не тотожні цикли. Тому при розробленні діагностичних алгоритмів застосовують процедури усереднення. Реальні електрокардіограми можуть мати значні спотворення окремих кардіоциклів, тому виникає потреба у визначенні нетипових циклів. У статті запропоновано алгоритм застосування метрики Хаусдорфа для визначення нетипових кардіоциклів електрокардіограми, поданої у тривимірному фразовому просторі координат.
\end{abstract}

Ключові слова: електрокардіограма, кардіоцикл, фразовий простір координат, метрика Хаусдорфа.

\section{APPLICATION OF THE HAUSDORF METRICS FOR DETERMINING ATYPICAL CARDIOCYCLES IN THREE-DIMENSIONAL VECTORCARDIOGRAM PHASE SPACE COORDINATE}

\author{
V. V. Vyshnevskey, T. M. Romanenko \\ Institute of Mathematical Machines and Systems, NAS of Ukraine
}

\begin{abstract}
Background. An electrocardiogram (ECG) is a cyclic but not a periodic signal. On the electrocardiogram, similar but not identical cycles can be distinguished. Therefore, diagnostic algorithms use averaging procedures. Real cardiograms may have significant distortion of individual cardiac cycles. We call these cycles atypical. These cycles should be distinguished and not used in averaging.

Materials and methods. To detect atypical cycles in the electrocardiogram, we form a three-dimensional phase space of coordinates using three ECG leads. ECG signals are pre-filtered and divided into cardiac cycles and elements. Each ECG cycle is presented as a three-dimensional curve arc. Each point of a curve has three coordinates. These coordinates are the values of the ECG in three leads at a certain point of time. For all pairs of three-dimensional curves, we calculate the Hausdorff metrics - the distance between each two curves. We consider atypical the cycles whose Hausdorf metrics will be significantly larger.

Results. The algorithm was tested experimentally on 142 individuals who were in different emotional and physical condition. Three ECGs have been recorded for each person. The first three ECG leads have been used to form curve arcs in the three-dimensional coordinate space. After calculating the Hausdorff metric, atypical cycles have been detected and removed from further calculations.

Conclusions. The Hausdorff metric in the three-dimensional phase space of coordinates is an effective tool for detecting atypical ECG cycles. The removal of atypical cardiac cycles from further calculations allows improving the results of identification of a person by his electrocardiogram.
\end{abstract}

Key words: electrocardiogram, cardiac cycle, phase space, Hausdorff distance.

\section{ПРИМЕНЕНИЕ МЕТРИКИ ХАУСДОРФА ДЛЯ ОПРЕДЕЛЕНИЯ НЕТИПИЧНЫХ КАРДИОЦИКЛОВ В ТРЕХМЕРНОМ ФАЗОВОМ ПРОСТРАНСТВЕ КООРДИНАТ ВЕКТОРКАРДИОГРАММЫ}

\section{В. В. Вишневский, Т. Н. Романенко}

Институт проблем математических машин и систем НАН Украины

\begin{abstract}
Сигнал электрокардиограммы (ЭКГ) относится к циклическим сигналам, в которых, в отличие от периодических сигналов, можно выделить подобные, но не идентичные циклы. Поэтому при разработке диагностических алгоритмов применяют процедуры усреднения. Реальные электрокардиограммы могут иметь значительные искажения отдельных кардиоциклов, поэтому возникает необходимость в определении нетипичных циклов. В статье предложен алгоритм применения метрики Хаусдорфа для определения нетипичных кардиоциклов электрокардиограммы, представленной в трехмерном фразовом пространстве координат.
\end{abstract}

Ключевые слова: электрокардиограмма, кардиоцикл, фразовое пространство координат, метрика Хаусдорсра. 
Вступ. Сигнал електрокардіограми (ЕКГ) відноситься до так званих циклічних сигналів. Цей тип сигналів, на відміну від періодичних, дозволяє виділяти подібні один до одного, але не тотожні цикли, в даному випадку — кардіоцикли. Тому, при розробленні діагностичних алгоритмів, для забезпечення сталих розрахунків амплітудно-часових характеристик кардіоциклів застосовують процедури усереднення. Оскільки реальні електрокардіограми можуть мати значні спотворення окремих кардіоциклів, що обумовлені як якістю електронних компонентів приладів, так і фізіологічним станом пацієнта, який може демонструвати нетипові кардіоцикли, наприклад, завдяки наявності в нього аритмії у вигляді екстрасистол. Тому, алгоритми усереднення кардіоциклів, що представлені в часовій області, можуть бути достатньо складними та передбачати, в тому числі, кластерний аналіз [6]. Як показано в [5], виділення нетипових циклів та усереднення циклічного сигналу значно простіше виконується в фазовому просторі координат, де немає осі часу. Для одноканальної електрокардіограми в [5] запропоновано використовувати фазовий простір, де за однією координатою використовується сам сигнал, а за іншою - його перша похідна. В якості метрики, що дозволяє знайти нетипові цикли, запропоновано використовувати метрику Хаусдорфа для двовимірного простору.

Стаття присвячена розширенню алгоритму застосування метрики Хаусдорфа, що описаний в [5] для тривимірного випадку векторкардіограми, яка складається з трьох ортогональних відведень, або для тривимірного простору, що складається з перших трьох відведень. Оскільки, саме такі випадки використовуються в $[3,2,1]$ для вирішення завдання ідентифікації пацієнта за його електрокардіограмою.

Мета роботи: розвиток методу застосування метрики Хаусдорфа для знаходження нетипових кардіоциклів та усереднення циклічного сигналу в двовимірному просторі координат, запропонованого в [5] для тривимірного простору координат, для вирішення завдання ідентифікації пацієнта за його ЕКГ, як викладено в [7, 2, 1, 3].

Матеріал і методи дослідження. Вихідні дані. Як показано в [5], двовимірний фазовий простір координат формується синтетично з сигналу одного відведення ЕКГ та першої похідної, обчисленої для цього сигналу. В нашому випадку використовуються три відведення ЕКГ для формування тривимірного фазового простору координат. Кожна точка на тривимірній кривій будується з використанням трьох координат, що отримані як значення в трьох відведеннях ЕКГ для однакового відліку часу. Отже, позбуваємося осі часу, замінивши її номерами відліків. На рис. 1 показано формування тривимірної кривої, що є послідовністю точок, координати яких є відповідними відліками в трьох відведеннях ЕКГ.
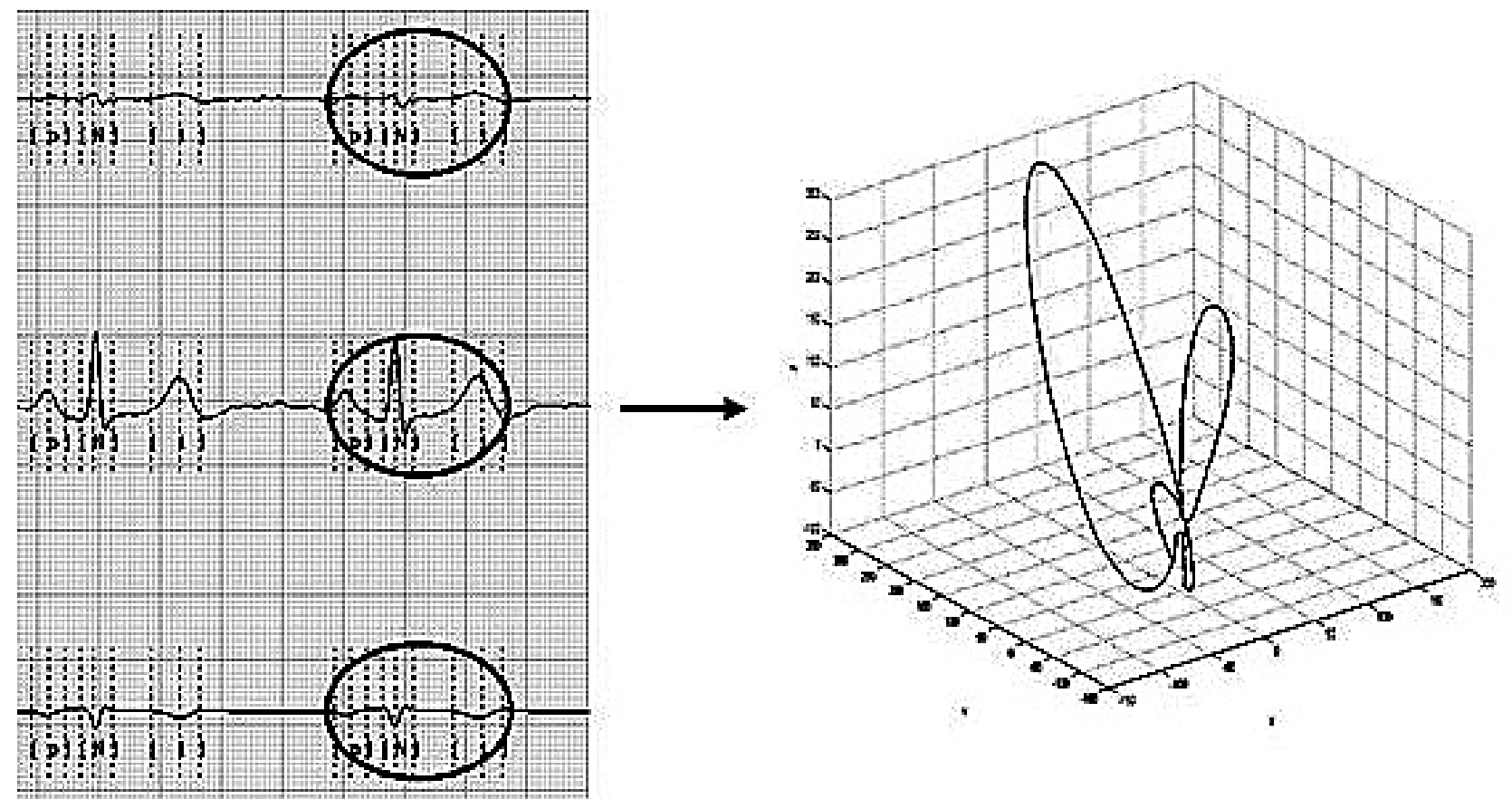

Рис. 1. Три відведення ЕКГта тривимірна дуга, що відповідає одному кардіоциклу 
Для формування тривимірного фазового простору координат можемо використовувати три ортогональні відведення ЕКГ, отримані безпосередньо або розраховані з дванадцяти стандартних відведень, три перших відведення з шести, синтетично створено за допомогою розрахунків з одного відведення ЕКГ. Такі варіанти отримання вихідних даних описано в патенті [1].

Для подальшої роботи виконуємо попереднє оброблення сигналів ЕКГ, що складається з фільтрації та розмітки - розділення на кардіоцикли та елементи циклів [6]. Для формування тривимірної кривої використовуємо частини всіх кардіоциклів від початку Р-інтервалу до кінця Т-інтервалу.
Алгоритм оброблення. Алгоритм визначення нетипових кардіоциклів полягає в наступному. Як вже було зазначено вище, попередньо оброблені три відведення ЕКГ дають нам можливість отримати послідовності значень координат для формування тривимірних дуг, що відповідають окремим кардіоциклам. Для цього відкладаємо по осях X, Y, Z значення напруги сигналів трьох відведень ЕКГ. Кожна ЕКГ складається з деякої кількості кардіоциклів, що в нашому алгоритмі представляються у вигляді множини тривимірних дуг кривих (рис. 2).

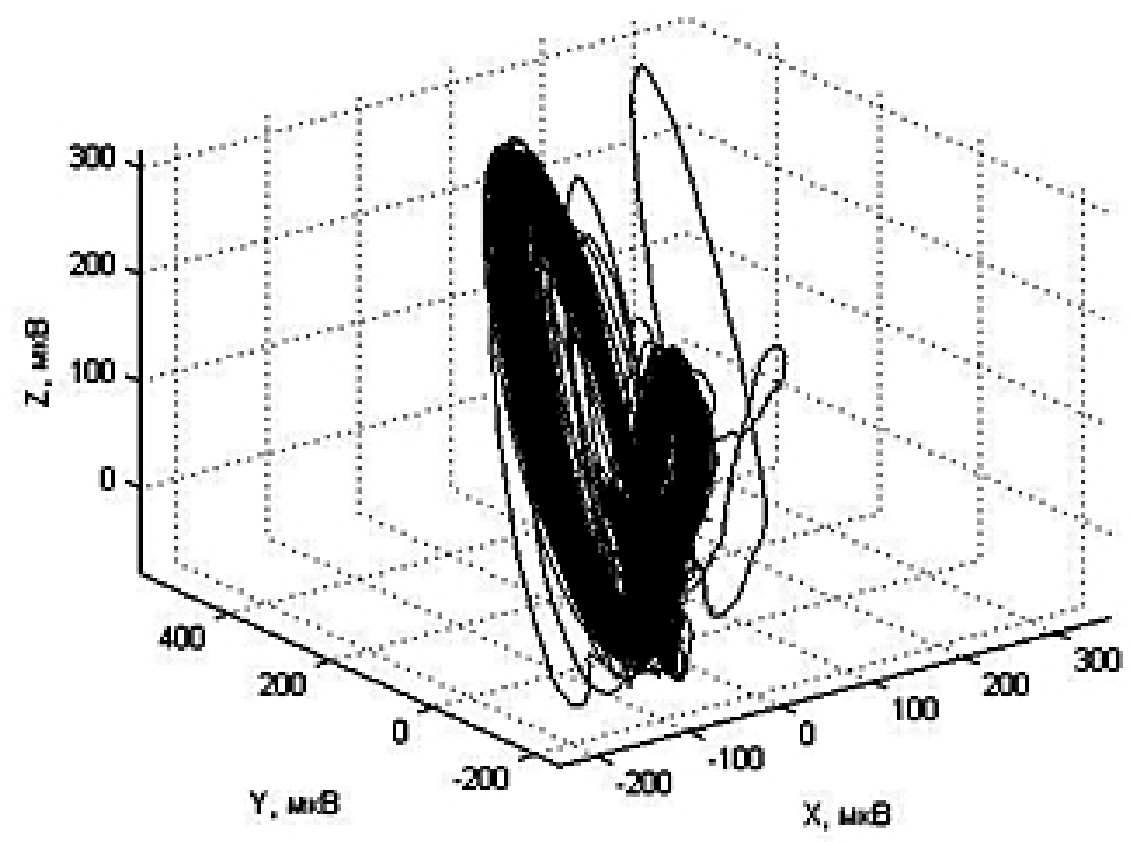

Рис. 2. Множина тривимірних дуг кривих, що відповідають усім кардіоциклам однієї ЕКГ

Як видно з рис. 2 частина дуг кривих, що відповідають певним кардіоциклам, суттєво відрізняється від більшості. Такі кардіоцикли вважатимемо нетиповими. Поява нетипових кардіоциклів може бути пов'язана із завадами при реєстрації кардіосигналу, суттєвими порушеннями форми кардіосигналу, іншими причинами. Врахування нетипових кардіоциклів у обчисленні характеристик усередненого циклу ЕКГ призводить до спотворення його форми. Тому нетипові кардіоцикли необхідно виявити та вилучити з розгляду до етапу подальших обчислень.

Для визначення нетипових циклів ЕКГ застосовували метрику Хаусдорфа у тривимірному просторі координат. Метрика Хаусдорфа — це відстань між двома кривими в тривимірному просторі координат. Кожна з цих кривих представлена множиною точок із трьома координатами. Обчислення метрики Хаусдорфа для двох множин точок виконуємо за такою формулою:

$$
\rho_{H}(A, B)=\max \left\{\max _{x \in A} \min _{y \in B} \rho(x, y), \max _{x \in B} \min _{y \in A} \rho(x, y)\right\},
$$

де $\boldsymbol{\rho}_{\boldsymbol{H}}(\boldsymbol{A}, \boldsymbol{B})$ - метрика Хаусдорфа для двох множин точок, $\boldsymbol{\rho}(\mathbf{x}, \mathbf{y})$ - метрика Хаусдорфа для двох точок із різних множин, А,B - множини точок, $\mathbf{x , y}$ - точки з цих множин.

Алгоритм обчислення метрики Хаусдорфа для двох множин точок включає такі дії:

- знаходимо мінімальну відстань від кожної точки першої множини до всіх точок другої множини; - серед них знаходимо максимальне значення це буде відстань від першої множини до другої;

— знаходимо мінімальну відстань від кожної точки другої множини до всіх точок першої множини; 
— серед них знаходимо максимальне значення це буде відстань від другої множини до першої;

- відстань Хаусдорфа для двох множин точок знаходимо як більше значення серед двох обчислених відстаней (від першої до другої множини і від другої до першої).

Цей алгоритм застосовуємо для всіх пар циклів ЕКГ, отримуємо таким чином матрицю Хаусдорфових відстаней між парами. Матриця має розмірність $\mathrm{N} \times \mathrm{N}$, де $\mathrm{N}$ - кількість циклів у ЕКГ. Для кожного циклу розраховуємо усереднене значення відстані Хаусдорфа від цього циклу до решти циклів цієї ЕКГ. Далі цикли ранжуємо за зростанням обчислених усереднених значень відстаней Хаусдорфа. Нетиповими вважатимемо ті цикли, Хаусдорфові відстані для яких будуть суттєво більшими, у порівнянні з більшістю циклів.

Результати та їх обговорення. Описаний алгоритм був перевірений експериментально. Для експерименту були зареєстровані електрокардіограми 142 людей різного віку та статі. Пацієнти знаходились у різному емоційному та фізичному стані, для кожного з них було зареєстровано по три ЕКГ. ЕКГ реєструвалися у шести відведеннях. Перші три відведення ЕКГ після попередньої обробки (фільтрація, розмітка на кардіоцикли та елементи циклів) використано для формування тривимірних дуг кривих у фазовому просторі координат. Для всіх кардіоциклів попарно були обчислені значення метрик Хаусдорфа, сформована матриця метрик та обчислені усереднені значення для кожного циклу. Після ранжування циклів за зростанням значень Хаусдорфових метрик і визначили нетипові цикли як такі, що мають значно більші значення цих метрик. Нетипові цикли вилучено з подальших розрахунків. Далі обробка включала в себе обчислення усередненого циклу, апроксимацію множини точок у тривимірному просторі, що відповідають кардіоциклу, параметричними сплайнами, за алгоритмами, наведеними в [7], та розділення на класи з метою ідентифікації людини. Вилучення нетипових кардіоциклів дозволило покращити результати ідентифікації завдяки більш вдалій апроксимації та кращому обчисленню усередненого циклу.
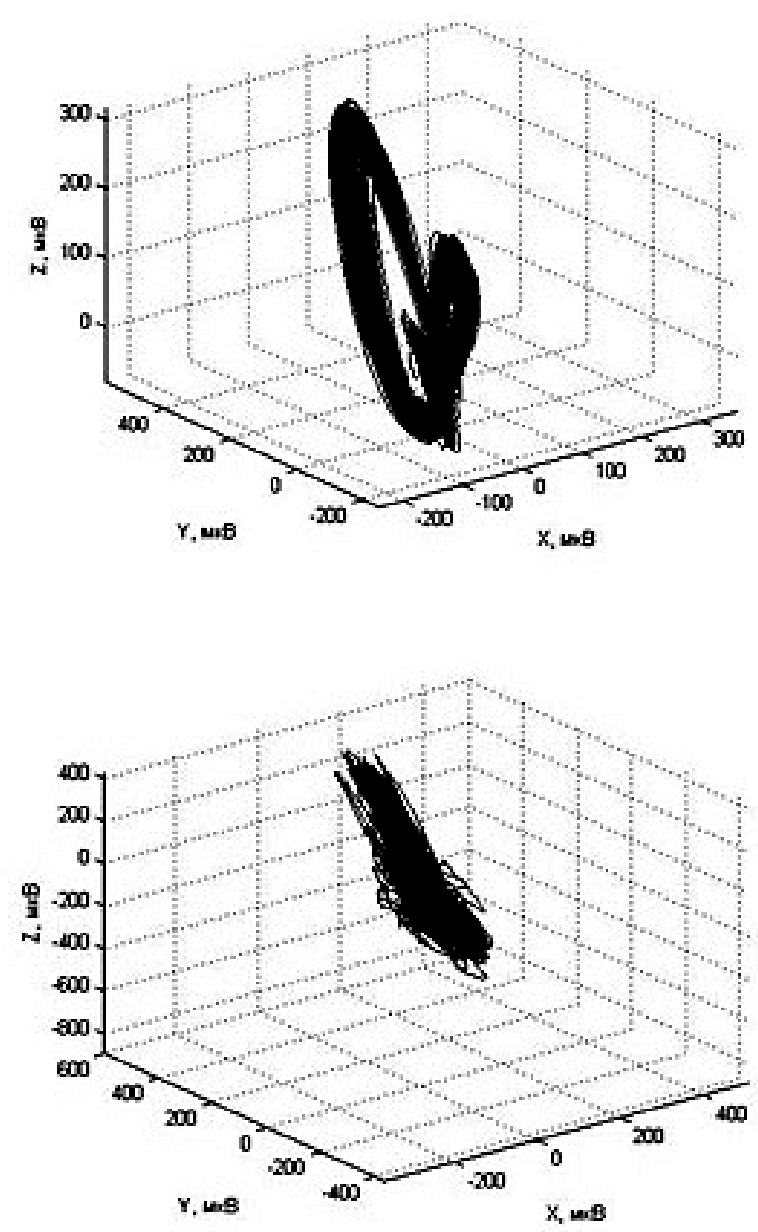


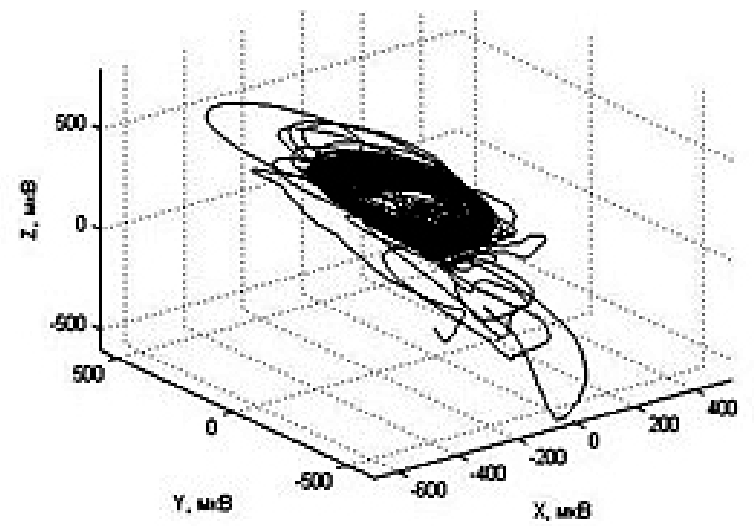

a)

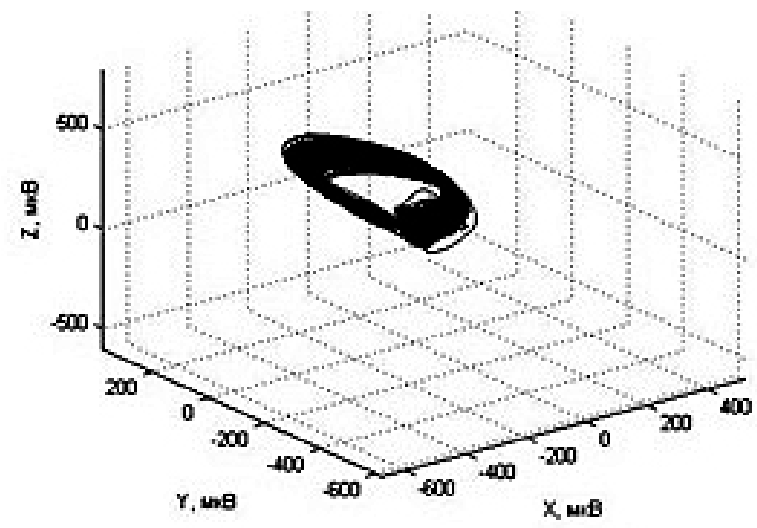

б)

Рис. 3. Три приклади ЕКГ: усі цикли ЕКГ, включно з нетиповими (а), цикли ЕКГ після вилучення нетипових, визначених за допомогою метрики Хаусдорфа (б) у тривимірному просторі координат

Як приклад, на рис. 3 наведено ЕКГ трьох різних пацієнтів. Поруч із усіма циклами ЕКГ у тривимірному просторі координат (а) зображено тільки ті цикли, що залишилися після вилучення нетипових, визначених за допомогою метрики Хаусдорфа (б).

Висновки. Метрика Хаусдорфа в тривимірному фазовому просторі координат є ефективним

\section{Література.}

1. Бібліографічні дані до патенту на винахід \# 117713 Спосіб автоматичної автентифікації людини за її електрокардіограмою. - Режим доступу: http://base.uipv.org/ searchINV/search.php?action=viewdetails\&IdClaim= 250654.

2. Вишневский В. В. Биометрическая идентификация человека по его электрокардиограмме / Вишневский В. В., Романенко Т. Н., Кизуб Л. А. // Математичні машини і системи. - 2018. - № 2. - С. 88-95.

3. Вишневський В. В. Усереднення QRS-комплексів електрокардіограми в ортогональних відведеннях / Вишневський В. В., Романенко Т. М., Чайковський I. А. // Системи підтримки прийняття рішень. Теорія і практика (СППР 2017): матер. міжнар. наук.-практ. конф. - К.: ІПММС НАНУ, 2017. - С. 83-84.

4. Вишневский В. В. Аппроксимация одно-, дву- и трехмерных дуг кривых параметрическими сплайнами / Вишневский В. В., Калмыков В. Г., Романенко Т. Н. // Математичні машини і системи. - 2015. № 4. - С. 57-64.

5. Файнзильберг Л. С. Восстановление эталона циклических сигналов на основе использования хаусдорфовой метрики в фазовом пространстве / Файнзильберг Л. С. // Кибернетика и системный анализ. - 2003. - № 3. - С. 20-28.

6. Чайковский И. А. Анализ электрокардиограммы в одном, шести и двенадцати отведени- інструментом для визначення нетипових циклів в ЕКГ. Вилучення нетипових циклів із розгляду при подальшого обчислення характеристик усередненого циклу, при апроксимації з метою ідентифікації та автентифікації людини дозволяє покращити отримані результати.

ях с точки зрения информационной ценности: электрокардиографический каскад / И. А. Чайковский // Клиническая информатика и телемедицина. - 2012. - № 2. - C. 102-106.

7. Vishnevsky V. Experimental Verification of Possibility of Human Identification by the Electrocardiogram / V. Vishnevsky, T. Romanenko, L. Kizub // Proceedings of the international conference on applications of information and communication technology and statistics in economy and education ICAICTSEE - 2015, November 13-14th, 2015, UNVE, Sofia, Bulgaria. P. 318-321.

\section{References.}

1. Bibliohrafichni dani do patentu na vynakhid \# 117713 Sposib avtomatychnoi avtentyfikatsii liudyny za yii elektrokardiohramoiu [Bibliographic data for the patent for the invention \# 117713 Method of automatic authentification of a person by his electrocardiogram]. - Retrieved from: http://base.uipv.org/searchINV/ search.php?action=viewdetails\&IdClaim=250654. [In Ukrainian].

2. Vishnevskey, V. V., Romanenko, T. M., Kizub, L. A. (2018). Byometrycheskaia identyfykatsyia cheloveka po eho elektrokardyohramme [Biometric identification of a person by his electrocardiogram]. Matematychni mashyny i systemy (Mathematical Machines and Systems), 2, 88-95. [In Russian]. 
3. Vishnevskey, V. V., Romanenko, T. M., Chaikovsky, I. A. (2017). Userednennya QRS-kompleksiv elektrokardiohramy $v$ ortohonal'nykh vidvedennyakh [Averaging of QRS-complexes of electrocardiogram in orthogonal leads]. Materialy mizhnarodnoyi nauk.-prakt. konf. «Systemy pidtrymky pryynyattya rishen'. Teoriya i praktyka (SPPR 2017)» (Materials of international scientific-practical. Conf. «Decision Support Systems. Theory and Practice (DSS 2017)»), 83-84 [In Ukrainian].

4. Vishnevskey, V. V., Kalmykov, V. H., Romanenko, T. M. (2015). Approksymatsyya odno-, dvu- i trekhmernykh duh kryvykh parametrycheskymy splaynamy [Approximation of one-, two-and three-dimensional arcs of curves by parametric splines]. Matematychni mashyny i systemy (Mathematical Machines and Systems ), 4, 57-64. [In Russian].

5. Fainzilberg, L. S. (2003). Vosstanovleniye etalona tsiklicheskikh signalov na osnove ispol'zovaniya khausdorfovoy metriki $v$ fazovom prostranstve [The restoration of the standard of cyclic signals based on the use of a Hausdorff metric in phase space]. Kibernetika i sistemnyy analiz (Cybernetics and System Analysis), 3, 20-28. [In Russian].

6. Chaikovsky, I. A. (2012). Analiz elektrokardiogrammy v odnom, shesti i dvenadtsati otvedeniyakh s tochki zreniya informatsionnoy tsennosti: elektrokardiograficheskiy kaskad [Analysis of an electrocardiogram in one, six and twelve leads from the point of view of information value: electrocardiographic cascade]. Klinicheskaya informatika i telemeditsina (Clinical computer science and telemedicine), 2, 102-106. [In Russian].

7. Vishnevsky, V., Romanenko, T., Kizub, L. (2015). Experimental Verification of Possibility of Human Identification by the Electrocardiogram. Proceedings of the international conference on applications of information and communication technology and statistics in economy and education ICAICTSEE - 2015, November 13-14th, 2015, UNVE, Sofia, Bulgaria, 318-321. 